\title{
The Impact of Cross-cultural Organizations on Teamwork Performance: A Yemeni Perspective
}

\author{
Zakarya Ali Qasem Ghalib \\ Xidian University, No.2 South Taibai Road, Xi'an, Shaanxi,China 710071
}

\begin{abstract}
This article discusses the most important analytical factors of cultural differences which are; Time and Work Patterns, Communication Style, Masculinity vs. Femininity, Conception of Space, Power Distance, and Individualism vs. Collectivism, Uncertainty Avoidance, and finally Custom Differences. These cultural factors examine the impacts on two types of Yemeni employees; the first type is employees with no cross-cultural practices and the second type is employees work in cross-cultural organisations.
\end{abstract}

Keywords: Teamwork, Cross-cultural Management, Yemenis’ Employees

DOI: $10.7176 / \mathrm{EJBM} / 11-14-13$

Publication date:May $31^{\text {st }} 2019$

\section{Introduction}

These cultural factors examine the impacts on two types of Yemeni employees; the first type is employees with no cross-cultural practices and the second type is employees work in cross-cultural organisations. Globalisation is a reality in the 21 st-century workplace. Therefore, leaders must function effectively in cross-border situations as well as in domestic contexts. According to Ward and Ravlin.(2017) Leaders working in cross-border contexts must cope effectively with contrasting economic, political, and cultural practices(Ward and Ravlin 2017). As a result, careful selection, grooming, and development of leaders who can operate effectively in our globalised environment is a pressing need for contemporary organisations.According to Gregersen et al. (1998), research on leadership effectiveness has been dominantly domestic in focus and does not necessarily generalise to global leaders (Gregersen, Morrison et al. 1998, House, Hanges et al. 2004). According to Johns (2006), there is a critical need for research that extends our understanding of how differences in context (domestic vs. cross-border) require different leadership capabilities (Johns 2006). As we build our arguments, we emphasise the importance of matching leadership capabilities to the specific context. Global leaders, like all leaders, are responsible for performing their job responsibilities and accomplishing their individual goals. Accordingly, general effectiveness, defined as the effectiveness of observable actions that managers take to accomplish their goals(Campbell, McCloy et al. 1993), is important for global leaders. We use the term "general" in describing this type of effectiveness because it makes no reference to a culture or cultural diversity. Thus, it applies to all leader jobs. According to Mladenović et al. (2017) Going beyond general effectiveness, it is crucial to recognise the unique responsibilities that leaders have when their jobs are international in scope and involve cross-border responsibilities(Mladenović, Mladenović et al. 2017). According to Dau (2016), Leadership in cross-border contexts requires leaders to (1) adopt a multicultural perspective rather than a country-specific perspective; (2) balance local and global demands which can be contradictory; and (3) work with multiple cultures simultaneously rather than working with one dominant culture(Dau 2016). Thus, we define cross-border effectiveness as the effectiveness of observable actions that managers take to accomplish their goals in situations characterised by cross-border cultural diversity. According to Shin, Morgeson et al. (2007), This aspect of global leaders' effectiveness explicitly recognises and emphasises the unique challenges of heterogeneous national, institutional, and cultural contexts (Shin, Morgeson et al. 2007).According to Mumford, Zaccaro et al. (2000), Effective leadership depends on the ability to solve complex technical and social problems (Mumford, Zaccaro et al. 2000). Given important differences in domestic and cross-border contexts, it is unlikely that leadership effectiveness is the same in domestic contexts as in crossborder contexts. In this article, we aim to shed light on these differences by focusing on ways that leadership competencies are similar and different in their relevance to different contexts (domestic vs. cross-border). When leaders work in cross-border contexts, the social problems of leadership are especially complex because cultural background influences prototypes and schemas about appropriate leadership behaviors. For example, expectations about preferred leadership styles, managerial behaviours, and the nature of relationships are all influenced by culture. Thus, effective cross-border leadership requires the ability to function in culturally diverse contexts. The objectives of the study are:

$>$ To identify the cultural factors affecting the Yemeni employees' culture.

$>$ To examine the impact of the identified factors ontwo types of Yemeni employees; the first type is employees with no cross-cultural practices and the second type is employees work in cross-cultural organizations. 


\subsection{Methodology}

With the intention of learning more about the impact of cross-cultural organizations on the employees' behavior and teamwork; a survey questionnaire was distributed which focuses only on the cross-cultural impacts on Yemeni employees and identifying the impact of culture differences. The survey was aimed at finding the dissimilarities among two types of employees; the first type is employees who work only on Yemeni environment and local companies, the second type is Yemeni employees who work in multicultural companies and experiencing cultural differences. The survey questionnaire I developed is based on the eight cultural factor components which discussed previously, this survey included about 30 questions and was distributed among 100 Yemeni employees; 50 people of the employees have never had any contact with other cultures, and the other 50 employees are working outside Yemen; who have been experiencing other cultures and had direct contacts with people from different countries. Although general intelligence (Judge, Colbert et al. 2004), as well as emotional intelligence, have been linked to leadership effectiveness in domestic contexts(Blum-Kulka, House et al. 1989), neither deals explicitly with the ability to function in cross-border contexts. To address the unique aspects of culturally diverse settings, Earley and Ang (2003) drew on Sternberg and Detterman's (1986) multidimensional perspective on intelligence to develop a conceptual model of cultural intelligence (CQ). Ang and colleagues(Ang, Van Dyne et al. 2007, Ang and Van Dyne 2008) defined CQ as an individual's capability to function effectively in situations characterised by cultural diversity. They conceptualised CQ as a multidimensional concept comprising metacognitive, cognitive, motivational, and behavioral dimensions(Ang and Van Dyne 2015).Metacognitive CQ is an individual's level of conscious cultural awareness during intercultural interactions. It involves higher-level cognitive strategies-such as developing heuristics and guidelines for social interaction in novel cultural settings - based on deep-level information processing. Those with high metacognitive CQ are consciously aware of the cultural preferences and norms of different societies prior and during interactions. They question cultural assumptions and adjust their mental models about intercultural experiences(Triandis 2006). Whereas metacognitive CQ focuses on higher order cognitive processes, cognitive CQ is knowledge of norms, practices, and conventions in different cultures acquired from education and personal experience. This includes knowledge of cultural universals as well as knowledge of cultural differences. Those with high cognitive CQ have sophisticated mental maps of culture, cultural environments, and how the self is embedded in cultural contexts(Nielsen and Nielsen 2011). These knowledge structures provide them with a starting point for anticipating and understanding cultural systems that shape and influence patterns of social interaction within a culture. Motivational CQ is the capability to direct attention and energy toward learning about and operating in culturally diverse situations. Kanfer and Heggestad (1997, p. 39) argued that motivational capacities "provide agentic control of affect, cognition, and behavior that facilitate goal accomplishment." Expectations and the value associated with accomplishing a task(Eccles and Wigfield 2002) influence the direction and magnitude of energy channeled toward that task. Those with high motivational CQ direct attention and energy toward cross-cultural situations based on their intrinsic interest in cultures(Deci and Ryan 1985) and confidence in intercultural effectiveness(Bandura 2002). Finally, behavioral CQ is the capability to exhibit culturally appropriate verbal and nonverbal actions when interacting with people from other cultures. Behavioral CQ also includes judicious use of speech acts - using culturally appropriate words and phrases in communication. Those with high behavioral CQ demonstrate flexibility in their intercultural interactions and adapt their behaviors to put others at ease and facilitate effectiveinteractions.Rooted in differential biological bases(Rockstuhl, Seiler et al. 2011), metacognitive, cognitive, motivational, and behavioral CQ represent qualitatively different facets of overall CQ - the capability to function and manage effectively in culturally diverse settings(Ang, Van Dyne et al. 2007, Ang and Van Dyne 2008). Accordingly, the four facets are distinct capabilities that together form a higher level overall CQ construct.Offermann and Phan (2002) offered three theoretical reasons for why leaders with high CQ capabilities are better able to manage the culturally diverse expectations of their followers in cross-border contexts (Avolio, Walumbwa et al. 2009). First, awareness of intercultural interactions allows leaders to understand the impact of their culture and background. It gives them insights into how their values may reflect bias their assumptions about behaviors in the workplace. It enhances awareness of the expectations they hold for themselves and others in leader- follower relationships(Dickson, Den Hartog et al. 2003). Second, high CQ causes leaders to pause and verify the accuracy of their cultural assumptions, consider their knowledge of other cultures, and hypothesise about possible values, biases, and expectations that may apply to intercultural interactions. Third, leaders with high CQ combine their rich understanding of self and others with motivation and behavioral flexibility in ways that allow them to adapt their leadership behaviors appropriately to specific cross-cultural situations. In addition to managing diverse expectations as a function of cultural differences, leaders in cross-border contexts also need to effectively manage the exclusionary reactions that can be evoked by cross cultural contact (Torelli, Chiu et al. 2011). Social categorization theory (Tajfel 1981, Turner, Hogg et al. 1987)theorises that exclusionary reactions to culturally diverse others are initially driven by perceptions of dissimilarity and viewing others as members of the out-group. Research demonstrates, however, that those with high CQ are more likely to develop trusting relationships with culturally diverse others and less likely to engage in exclusionary reactions(Rockstuhl and $\mathrm{Ng}$ 2008). Figure 1 depicts the EQ perceptions. 


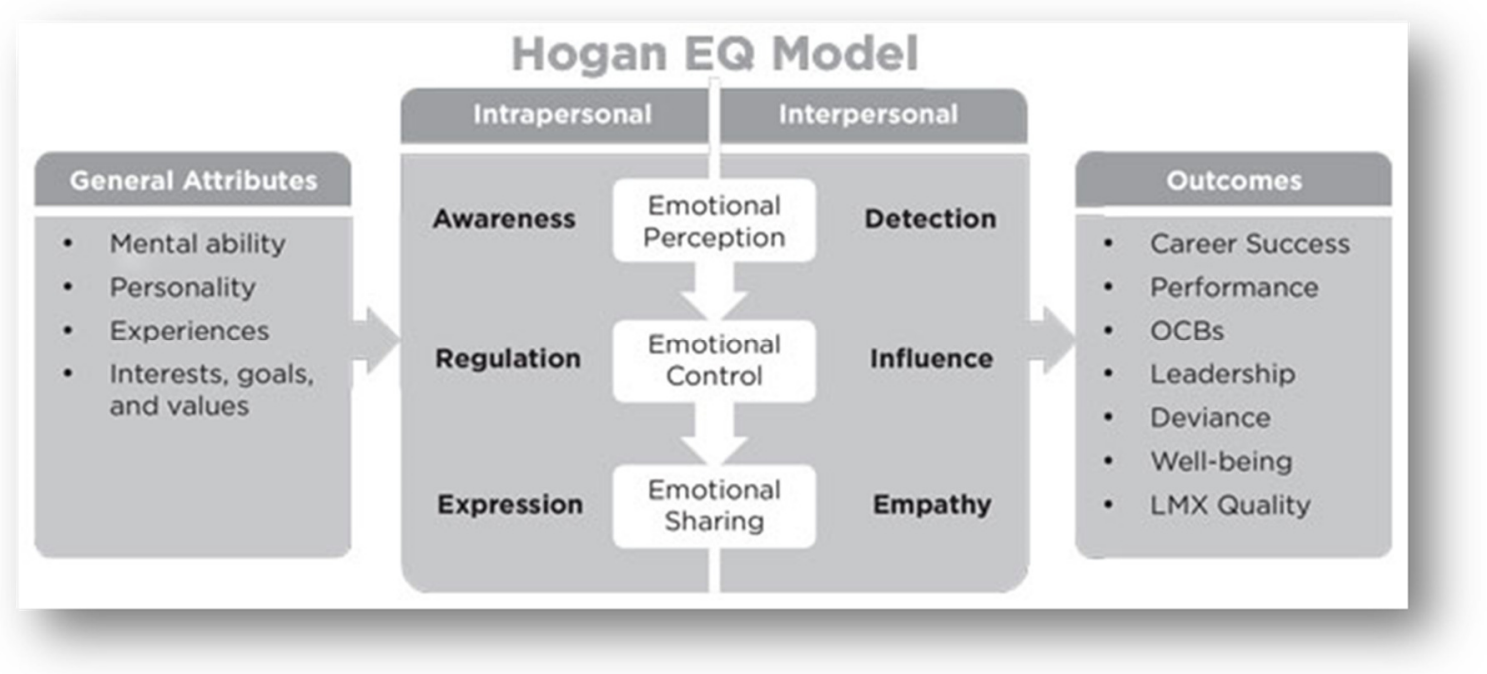

Figure 1. the EQ perceptions

Consistent with our earlier emphasis on matching capabilities to the context, their results also demonstrated that CQ did not influence trust when partners were culturally homogeneous. An increasing amount of research demonstrates the importance of CQ for performance effectiveness in cross-border contexts (for reviews, see Ang, Van Dyne, \& Tan, 2011; Ng, Van Dyne, \&Ang, in press). This includes expatriate performance in international assignments (Chen, Kirkman et al. 2010), successful intercultural negotiations (Imai and Gelfand 2010), leadership potential (Kim and Van Dyne 2012), and leadership effectiveness in culturally diverse work groups (Groves and Feyerherm 2011). To summarise, theory and research support the notion that leaders with high CQ should be more effective at managing expectations of culturally diverse others and minimising exclusionary reactions that can occur in cross-border contexts. Thus, we hypothesise that general intelligence will predict leadership effectiveness in domestic contextsand cross-border contexts; emotional intelligence will be a stronger predictor of leadership effectiveness in domestic contexts; and cultural intelligence will be a stronger predictor of leadership effectiveness in cross-border contexts.

1. To say that globalisation is upon us is axiomatic. Conducting global, international, and cross-cultural business is a mundane reality for most contemporary large organisations. Even if your business is a medium- or small-sized firm, you have probably experienced globalisation through interactions with global participants that belong to at least one, or perhaps more, of these four key categories: customers, competitors, suppliers, or employees. Global business is already a substantial force in the world's economy: The World Trade Organization reported that, in 2003, international trade comprised $30 \%$ of global GDP. In their book Race for the World, Lowell L. Bryan et al. (1999) predicted that, by the year $2029,80 \%$ of world output would be in global markets. Thus, while globalisation has arrived, the full extent of its impact on business has yet to be felt. If growth in international trade continues as expected and predictions for its eventual size hold true, global business will see at least a twofold increase. Such dramatic changes in the conduct of business require leadership from individuals skilled in global aspects of business functions such as marketing, operations, finance, human resource management, information management, and R\&D. However, global leaders must also be extremely skilled in the interpersonal conduct of global business. This requires emotional and cultural intelligence, the focal points of this article. Unfortunately, while the need for global business leaders has never been so urgent, serious deficiencies exist in the preparation of corporate managers as they deal with the interpersonal realities of global business. In a comprehensive review of the global leadership literature, VesaSuutari (2002) came to the following conclusions: Leaders need to develop global competencies.

2. There is a shortage of global leaders in the corporate world.

3. Many companies do not know what it means to develop corporate leaders.

4. Only $8 \%$ of Fortune 500 firms have comprehensive global leadership training programs.

5. There is a need to better understand the link between managerial competencies and globalleadership.

Similarly, Tracey Manning (2003) summarised the research of many leadership scholars and found that multinational companies' efforts to develop effective global managers fell far short of the optimum:

$>85 \%$ of Fortune 500 firms surveyed did not have an adequate number of leaders.

$>65 \%$ felt their leaders needed additional skills.

> One-third of international managers underperformed in their international assignments based on their superiors' evaluations. Organisations have erroneously promoted leaders to international 
assignments based on technical and organisational skills.

Ultimately, the negative consequences of wrong leadership choices are both expensive and well-publicized. And while the overall picture of global leadership development indicates businesses are not pursuing this matter sufficiently, the outlook is even bleaker regarding the development of global leaders' emotional and cultural intelligence. Although some firms are endeavoring to enhance the emotional intelligence capabilities of their leaders, very few have moved to grow culturalintelligence, as awareness of this important concept is still at an early stage. In this article, we discuss the concepts of emotional and cultural intelligence, why they are critical to successful global leadership, and how they may be developedin global leaders.

Culturally attuned and emotionally sensitive global leaders need to be developed: leaders who can respond to the particular foreign environments of different countries and different interpersonal work situations. Two emerging constructs are especially relevant to the development of successful global leaders: cultural and emotional intelligence. When considered under the traditional view of intelligence as measured by IQ, cultural, and emotional intelligence provide a framework for better understanding cross-cultural leadership and help clarify possible adaptations that need to be implemented in leadership development programs of multinational firms. To talk about the Arabic culture, I have to use the model I developed byUser's model 'sources of culture'. The model is as shown below see figure 2:

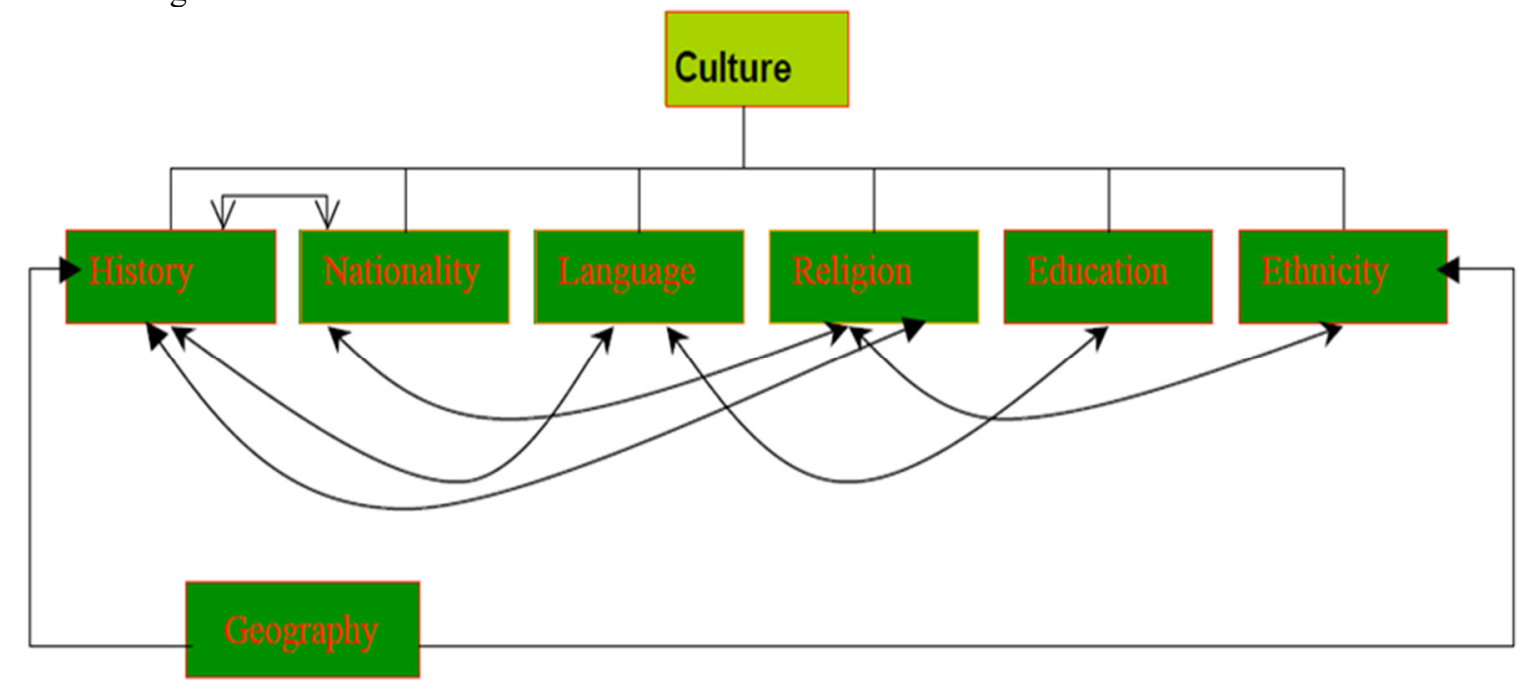

Figure 2. Arabs cultural indicators perceptions

The present-day Arabs do not only live where the Arabs once were. The region was under different waves of immigration since the first wave of the Sumerians whosuggested to be of central Asian origins and up to day were millions of immigrant workers from southern countries of Asia, e.g., Filipino, Indian, Thailand's migrants. The Arabs moved out of the Yemen in the early part of the current era mainly to northern Arabia, then the major movement of Arabs was from Najd of Central Arabia particularly after the rise of Islam. The ancient monuments found here by the archaeologists derive the history of the region up to the year 7000 B.C, with the first urban center, the first written law, and most important of all the inventions (what Arabs call the soul of the inventions) the writing. "The popular story goes, however, that (Arab) civilisation started at Sumer, and soon the rising of the City State, which led to the modern states, the new kingdoms, many of which later occupied their neighbors. In this light the geographical area was characterized by relative prosperity (there are reports of advanced Assyrian commercial organizations about the year 2000 B.C., with organizations operating with head office, branches, etc. Looking very similar to modern MNC's: employees, nurturing new foreign markets, see More and Lewis 1999). As the homeland of the three main divinely religions Judaism, Christianity and Islam, in addition to many other local or regional religions, such asYazidis, Mondays, the religious rituals, values and taboos has played a main resource of the cultural identity of the people in this region. Despite Turkey and Iran, the people in this region, mainly are Arabs Muslims, the majority are Sunni Muslims in all these countries except in Iran where the majority are Shiites. However, this does not deny the fact that there are some ethnic or religious minorities in these countries, such as Shiites in Saudi Arabia, Syria, Iraq, Bahrain and Lebanon, and a good sum of Christians almost in all these countries, there said to be no Christians in Saudi Arabia. However, the region was caught between large empires fighting each other, the Seljuk 1055, the Byzantines in 1071 followed by the Mongols from 1200 to 1300 . Since 1301 the great Ottoman sultans were the new rulers. The Ottoman Empire was involved in many wars with the Persian Empire, using the Arab land as the field of their battles. Romans, Turks, Egyptians and Ethiopians occupied or conquered parts of the Arabic Middle East, until the beginning of the twentieth century when oil was discovered! The new European empires caught and divided the region between them (Iraq, Jordan, Palestine, the Gulf towns 
which became a mini states under the English protection, and Egypt) these were under the British mandating. While Syria, Lebanon, and some of the North African countries were the French piece of cake. These historical facts can explain the contradicting dimensions of the Arabic culture, in the way that each of these cultures contains a contrasting set of synthetic culture profiles; while cultures in these countries can be described as collectivist cultures, there are a lot of the individualist characteristics in their core beliefs, and the same is valid in other dimensions as I will describe later.This is by some authors presented as the key reason behind the rather similar language and the large proportion of ethnic minorities. Because of these facts, it is deceptive to try identifying national cultures as based on very recently established nation states. Current borders have been established post first world war after being moved several times through history. As in their view of the area of Sham is considered a complete region by the Arabs even if outsiders into Syria, Lebanon, Palestine/ Israel, and Jordan split it. This way, inhabitants in this region have a more shared history, and comparing cultures based on very recentnational borders seems less relevant. For us to investigate and understand any country's culture, we must learn the basic information and elements which affect the culture, such as geography, history, religion, location society and economic situation. Yemen is an Islamic Arabic country in the Middle East; it is in Western Asia. The country's first language is Arabic, and its culture is heavily influenced by historical events and religion. As statistics show that the population in Yemen is 30 million and $98 \%$ of the population follows the Islamic religion. Yemen is one of the oldest civilisations and ancient country, and it is called the origin of the Arabic countries in the Middle East. I believe that Yemen has an attractive locationsince it is the door that links the Middle East countries with South African countries. So as a result, the history shows that strong countries over the years to try to take control over this country for accessing countries in the region. Talking about the Yemeni history, in 1918 North Yemen became independent of the Ottoman Empire and the British, who had set up a protectorate area around the southern port of Aden in the 19th century; they withdrew in 1967 from South Yemen and in 1990 South Yemen, and North Yemen were formally unified as the Republic of Yemen. This country's land is rich and adequate rainfall; it has Five cities are formally announced to be Nature Reserve, an ancient Greek geographer Ptolemy, who described Yemen as Eudemon Arabia meaning "fortunate Arabia" or Happy Arabia. Yemeni is a gorgeous country famous for its diversity in weather, Architectural Embellishment, silver, coral, Ornaments decoration which shows in the pictures below. Yemen is popular for Temperate in the mountainous regions in the western part of the country, extremely hot with minimal rainfall in the remainder of the country. The country is rich in natural resources which are oil, seafood, coal, copper and natural gas. Also its agricultural products are Coffee, cotton, fruits, and vegetables.

\subsection{Results}

\section{Time and Work Pattern}

The first cultural factor is Time and Work Patterns, the differences in this factor among the two types I found that the Yemeni employees who work only in local companies without any contact with other cultures work less than employees in cross-cultural companies, with the results showed in Table1; I found that $80 \%$ of the local workers work 5 to 7 hours a day whereas, for the cross-cultural workers, $90 \%$ tend to work 8 to 10 hours and $10 \%$ work more than 11 hours a day.In addition, I found that local Yemeni workers are more conservative and worried about their own personal life and issues, with only $20 \%$ of local workers who are willing to discuss personal issues with their colleagues, they say it depends on the person and situation and $80 \%$ says that they never talk about personal issues. However, for the cross-cultural workers, $60 \%$ say that they do not usually talk about their personal life and $40 \%$, says they discuss about their personal lives with their co-workers.

Table1: Time \& Work Patterns Differences:

\begin{tabular}{|c|c|c|c|}
\hline Primary Index & Secondary Index & Only Yemeni Employees & Yemeni in Cross-cultural \\
\hline \multirow{4}{*}{$\begin{array}{l}\text { 1. Time \& Work } \\
\text { Patterns }\end{array}$} & Working Time & 5 to 7 hours / day ( $80 \%$ people $)$ & $\begin{array}{c}5 \text { to } 7 \text { hours / day }(90 \% \\
\text { people })\end{array}$ \\
\hline & Personal issues & Do not share & More open to share \\
\hline & Time orientation & Past-oriented \& short term & $\begin{array}{l}\text { Present, future -orientated \& } \\
\text { moderate short term }\end{array}$ \\
\hline & $\begin{array}{l}\text { Modality of human } \\
\text { activity }\end{array}$ & Moderate Doing & High Doing \\
\hline
\end{tabular}

Moreover, there was one surprising reaction I found while I was interviewing some local employees, four people out of ten were shocked when I asked them about if they share personal issues with their colleagues, at first they were not happy when they heard this question and then they were telling me that I should delete it from the survey. However, I convinced them that this question is very important for the results I am hoping to find and I cannot deleteit, and I want them to give me their answer which NO. was obviously from this, I can see that local workers are very conservative and protective of their private life, and it is not polite for anyone to ask you about this subject. Consequently, from this result, we can observe that local employees work less and they are less likely 
to share their personal issues with others and their cultural factors are past-orientated which means that tradition and events from history are highly affecting their actions, also they are conservative with being moderate of making changes and willing to accomplish things. Unlike the cross-cultural employees, they work more, and they are more open to others, they also think about the present and future orientated with the fact that they are enrolling under the high doing and willing to achieve their goals.

\section{Communication Style}

The second cultural factor is Communication Style, there have been many studies on the importance of relationship and connections in Yemen, along with I can say that the connections is one of the basics of every communication and relationships in workplace, which means that it is very important and easier for employees in local companies to get a high position in their work if they have a strong connection or mediation, consequently developing a solid personal relationship with a colleague or client is key to any business relationship within Yemen. Having a good relationship with key individuals can make all the difference in making or breaking the deal. The best way to establish a strongrelationship is to socialise with the client or colleague in casual times. It is also important to maintain frequent contact via phone as a sign of courteousness. In my opinion, this is because Yemen is a developing country and its government officials are famous for their corruption, and bribes involve in the process of completing transactions or promoting workers and giving high positions to people with connections this called in Chinese as Guanxi. However, for cross-cultural companies the situation can be entirely different, and the influence of recruiting employees and promoting is based on fair evaluation and it is completely based on qualifications and performance so that this gives workers the incentive to work harder and perform better so that they will be motivating for them to participate better and achieve goals since they feel that their performance will be evaluated fairly and each person will be rewarded according to their achievement. Throughout many studies and my interview, which shown in Table2; I have noticed that the local workers are the high context in their communication with others which means that they do not usually say what they think of in a clear way and sometimes their words may mislead the receiver and make him understand something differently. However, for those people who have experienced working with different cultures, they understand that a person should illustrate clear messages when he talks as much as they can so that the receiver will not be misunderstanding his real meaning. So that the communication between workers in the cross-cultural companies are more effective and clear than the local companies, especially to the point that in cross-cultural companies, employees respect and accept the fact that everyone is different and we have to explain our ideas and thoughts to others.

Table2: Communication Style Differences:

\begin{tabular}{cccc}
\hline Primary Index & Secondary Index & Only Yemeni Employees & Yemeni in Cross-cultural \\
\hline & Guanxi\&Renqing & High & Low \\
2. Communication Style & Context & Moderate-high & Moderate-low \\
& Gender Space & Huge space $(90 \%)$ & Huge space $(30 \%)$ \\
& & Not Huge $(10 \%)$ & Not Huge $(70 \%)$ \\
\hline
\end{tabular}

There is one more aspect I must mention in this result is that there is one tradition that significantly changes among the two types; this aspect is called the Gender Space which represents the communication between males and females. Table2 above shows that I found that there is a huge gap in communication between males and females among local employees, $90 \%$ of local employees say that when they talk to their female co-workers, they pay attention to the space between them and they must talk to them formally and with high boundaries. Whereas, for employees in cross-cultural companies, from the data I have collected I can see that gender space has become less with the fact that only $30 \%$ think that gender space is extremely important and $70 \%$ think that they do not find problems when they communicate with female co-workers and they do not have big space or high-level restrictions as much as there is among local employees. From this we can see that there are an easiness and flexibility in the communication style in cross-cultural companies, comparing it to local companies and this make communication and teamwork performance more accurate and efficient.

\section{Power Distance}

The third cultural factor is Power Distance, in Table3 it shows that local employees $90 \%$ say that managers have strong control and they always have the power to make decisions without referring to workers, also due to some studies which have been done, it is said that the power distribution among Yemeni workers are highly unequally distributed which means that there will be a huge gap between those people who control rules and decisions and those people who do not have any power and they cannot change things or make decisions. Accordingly, with this high-power distance and unequal power distribution, we can observe that fairness and satisfaction is a great problem among Yemeni workers, and this might have negative impacts on employees' performance and willingness to work hard and achieve goals. On the other hand, this problem can be less with cross-cultural companies because the situation will be completely the opposite and the only parameters for achievement will be performance and achievements so this will encourage workers to perform the best they can. 
Table3: Power Distance Differences:

\begin{tabular}{cccc}
\hline Primary Index & Secondary Index & Only Yemeni Employees & Yemeni in Cross-cultural \\
\hline & Distance & High & Medium \\
Distribution & Unequal & More equal \\
3. Power Distance & Change job $(10 \%)$ & $\begin{array}{c}\text { Change job }(18 \%) \\
\text { Complain to the manager }\end{array}$ \\
& Response to Unfair & Complain to the manager & $(50 \%)$ \\
& & talk to him $(20 \%)$ & talk to him $(22 \%)$ \\
& complain to friends $(28)$ & complain to friends $(10 \%)$ \\
\hline
\end{tabular}

Yemeni employees, in general, do not remain silent against injustice; instead, they will always ask for fairness and will fight for their rights and justice. However, there is a slight difference between the two types of employees. I found that cross-cultural Yemeni employees are more willing to fight for their rights and in the case of serious unfairness they say that they are ready to change their job. Whereas local employees will complain slightly less to their managers, in contrast, they will complain to their friends and family.

\section{Masculinity \& Femininity}

Masculinity vs. Femininity, is the fourth cultural factor in this factor local employees and cross-cultural employees are both consider to be Masculinity, but both are different in percentages; in the survey data explained in Table4 which says that $64 \%$ of local employees planning to recruit only male workers and $36 \%$ are willing to recruit employees depending on their qualifications and experience. At the same time, $80 \%$ of cross-cultural employees are willing to choose a qualified employee and the gender differences is not an important factor with the fact that only $20 \%$ think that gender is an important factor for recruiting employees. Furthermore, if we are talking about forming teamwork, we can observe from the data that in local companies there is $80 \%$ prefers only males on their teamwork and for cross-cultural employees, $70 \%$ claims that It does not matter to have males or females as much as qualification and high performance. This shows that there is a significant problem when a task requires teamwork, because, with the high masculinity among local workers, this makes them unable to have effective communications and discussions with their female co-worker. So at this point I think cross-cultural employees are more effective in their teamwork performance so that they will have a better outcome and performance as one group.

Table4: Masculinity vs. Femininity Differences:

\begin{tabular}{cccc}
\hline Primary Index & Secondary Index & Only Yemeni Employees & Yemeni in Cross-cultural \\
\hline & Gender Difference & Recruit Male (64\%) & Recruit Male (20\%) \\
& Qualification (26\%) & Qualification (80\%) \\
4. Masculinity & Teamwork Co- & Male only (80\%) & Mixture $(70 \%)$ \\
Vs. Femininity & operation & Refuse (74\%) & It is Okay (70\%) \\
& Female Managers & Don't Like (26\%) & Do not Like $(30 \%)$ \\
\hline
\end{tabular}

One more point I have found through my survey is that $74 \%$ of local employees are not willing to work in a job where their female manager and actually they say they look for another job because they think that female managers are not as qualified as male managers and they also think that the controlling statute is only for males, the other $26 \%$ still do not like to work with female managers, but if they had to they would work with female managers.On the other hand, cross-cultural employees have a completely different point of view, $70 \%$ say that it is okay to have female managers and they do not have any problems with this situation and actually big percentage are working with female manager, the other $30 \%$ still do not like to have a female manager, but at the same time they will not argue against that.

\section{Conception of Space}

The fifth cultural factor is Conception of Space; in this factor, the local employees and cross-cultural employees do not have the same sensitivity to private questions, from the survey as I mentioned above, local employees are very sensitive to privatequestions and they even feel more insulted if anyone discusses private issues with them. But cross-cultural employees are more open-minded about the restrictions on private questions; they think that it is okay to share some private issues with colleagues and do not, which shows that the cross-cultural employees are more tolerant and flexible while communication with others and they have less space which makes it easy to get close to and create strong relationships with which impacts the teamwork performance positively. Talking about the physical space, I have pointed out earlier that gender space is very important in the Yemeni culture especially to the local employees. However, I can say that local and cross-cultural employees have similar physical space when the same gender is communicating with each other. Conversely, if the two different genders communicate with each other the situation is completely different and we can say that with local employee's physical space matters extremely and for cross-cultural employees the physical space has become less important, and it is not 
such a problem to communicate with the other gender as it is in the situation with local employees.Furthermore, in Table5, It also shows how the two types of Yemeni employee response to the centre/ power of the community; we can say that local employees are not similar to cross-cultural employees, where there is $66 \%$ of local employees enjoy being the centre of community and $34 \%$ of to be the power of community. However, for cross-cultural employees, $54 \%$ of the employees prefer to be the power of community and $46 \%$ choose to be the center of the community. From this, we can detect that cross-cultural

Table5: Conception of Space Differences:

\begin{tabular}{cccc}
\hline \hline Primary Index & Secondary Index & Only Yemeni Employees & Yemeni in Cross-cultural \\
& Private Question & Highly Sensitive & Moderate-Sensitive \\
5. Conception of space & Physical Space & Huge & Less \\
& Centre of & Centre of Community (66\%) & Centre of Community (46\%) \\
& Community/Power & Power of community (34\%) & Power of Community (54\%) \\
\hline
\end{tabular}

\section{Individualism \& Collectivism}

Individualism \&Collectivism are the sixth cultural factor, in this factor we found that Local and cross-cultural employees are both considered to be collectivism since both of them enjoy being in teamwork more than working individually. However, cross-cultural employees are moderate high collectivism with $60 \%$ as shown in Table6, and they enjoy being in teamwork, and only $20 \%$ like to work individually, and the rest say that sometimes they like to work individually and others with groups. For local employees there are $46 \%$ who enjoy working with teamwork and $30 \%$ sometimes individually and sometimes within groups, when we first see that we will see that there is not a big difference in participating in teamwork, however, we have to remember that there is a big dilemma with local employees with working in teamwork with female workers. So, in my opinion, for them, teamwork will be less effective and it will be hard for them to achieve their tasks with broad-mindedness and as effective as crosscultural employees will perform teamwork tasks and responsibilities.

Table6: Individualism vs. Collectivism Differences:

\begin{tabular}{cccc}
\hline Primary Index & Secondary Index & Only Yemeni Employees & Yemeni in Cross-cultural \\
\hline \multirow{2}{*}{ 6. Individualism } & Small Group & Moderate Collective & Moderate-high Collective \\
Vs. & Team Work & Yes $(46 \%)$ & Yes $(60 \%)$ \\
Collectivism & & Nometimes $(30 \%)$ & No $(20 \%)$ \\
& Ask for Help & Moderate & Moderate \\
& Aural Space & Moderate, Complain & High, Complain \\
\hline
\end{tabular}

Two more elements of this factor are asking for colleagues' help and aural space, for asking for help element I found that both types have the same characteristic. But for aural space, employees in cross-cultural companies tend to complain more about the noise around them or anything that disturb their workplace environment. From these points, we can see that collaborating and cooperating will be strapping, and employees will have stronger teamwork performance.

\section{Uncertainty Avoidance}

The seventh cultural factor is Uncertainty Avoidance, from previous studies, have been on the Yemeni workers, it says that usually, Yemeni people, in general, do not follow the rules and usually break the rules, however, if there are a strong enforcement and implementation of rules by the government and law they are more likely to respect the rules and be well-mannered.In addition, to compare these studies to the data and result, I got from this survey I can say that Cross-cultural employees are more considerate to rules than local employees and this is due to the fact that there is no enforcement of the rules of the Yemeni society, and moreover, Yemeni people believe that those officials in the government who make the rules are the first ones to break and disregard rules.One important point explained in Table7 regarding to uncertainty avoidance is cautiousness and carefulness about tasks' small details and information, Yemeni employees, in general, believe that if they ask many questions related to their work, this will give them bad reflection and it will only represent their weakness and less skill, so that both local and cross-cultural employees do not like to ask their managers or colleagues about little information or so many questions and concerns. This has two side effects; the advantage is that this makes them responsible for achieving tasks without having to ask their managers for directions and advice so that they will be more productive and creative. The other side is a negative side, which is represented as having less communication with others and this might lead to alack of sharing information and experiences so mistakes might be repetitive. In my point of view, I think not asking about little information is an advantage in the teamwork performance in general, because I believe that if employee managers give employees every little information and instructions this will make them less capable of being responsible and dependent while it comes to making quick decisions and this is a destruction of their talent and the ability to be original, resourceful, creative and inventive. 
Table7: Uncertainty Avoidance Differences:

\begin{tabular}{cccc}
\hline Primary Index & Secondary Index & Only Yemeni Employees & Yemeni in Cross-cultural \\
7. Uncertainty Avoidance & $\begin{array}{c}\text { Observe the Rules } \\
\text { Carefulness }\end{array}$ & Not much & Follow \\
& Not little info (untalented) & Not little info (untalented) \\
\hline
\end{tabular}

Lastly, the eighth cultural factor is Custom Differences, this factor is mainly focusing on some other traditional differences that each country and culture have, and of the Yemeni culture there are many customs and traditions which are important and significantly impact people. Some of these important factors are Religion, Dressing and Humane Orientation. The result, I found from the questionnaire showed in Table8 which is some of these traditions are becoming less effective and influencing to cross-cultural employees, and I think this is a good thing because it also makes employees more willing to accept differences with others and accept.

Table8: Custom Differences:

\begin{tabular}{cccc}
\hline Primary Index & Secondary Index & Only Yemeni Employees & Yemeni in Cross-cultural \\
\hline \multirow{3}{*}{ 8. Custom Differences } & Religion & Important & Important \\
& Dressing & Conservative & Less Conservative \\
& Humane Orientation & Religion(caring) & Religion (caring) \\
\hline
\end{tabular}

One other main factor is dressing; it is very important to the Yemeni individuals and for both genders to follow the tradition of wearing and dressing which is very conservative. It is essential for people to dresslong clothes, show less skin, and avoid wearing tight clothes. These restrictions are necessary and actual in the society. Nevertheless, from the results I got, cross-cultural workers are choosing to be less concern about the dressing, and they have a propensity for wearing whatever they think is suitable for them and looks good on them even if it is not conventional. Accordingly, from these changes we can see that cross-cultural practices are influencing the Yemeni employees in a positive way since they have become more flexible and accepting the fact that everyone is different and have the choice to make his or her preference. Furthermore, this flexibility is impacting the employees' behavior in the workplace and has direct and indirect impacts on employees' relationship which highly impact their performance as teamwork and the outcome of their interaction. So, the changes in Customs among cross-cultural employees will benefit the organisation and will increase teamwork competence and productivity. In the following paragraphs I will be explaining the impacts of cross-cultural organizations on Yemeni employees' performance and teamwork interactions; I will be providing how the behaviour and perceptions have changed among Yemeni employees in local organizations and cross-cultural Yemeni employees, this will show how the transformation of a cross-cultural organization is changing the cultural factors explained previously. Summarizing the comparative study of the eight factors of cultural differences among Yemeni employees, we can see that each factor and its impacts on Yemeni employees support the idea of cross-cultural organizations. Since cross-cultural organizations have a strong positive impact on employees' performance and willingness to achieve better communication and effort which lead to efficiency and creativity. I will start by explaining the impacts of the first factor on Yemeni employees, which is time and work patterns; from the survey's results, I found that cross-cultural interactions changed Yemeni people from being short-term orientation to long-term orientation, which means that cross-cultural Yemeni employees do not accept delaying projects and establish long-term relationships. Thus, I think this makes Yemeni employees hardworking and serious about time, so this will lead them to be more conscious about completing tasks during the giving time and extremely pay attention to project deadlines. Communication style and power distance factors have strong impacts on cross-cultural Yemeni employees; I mentioned earlier that there are strong restrictions, formality, inequality and power distribution are high in the Yemeni culture which impacts the employees' willingness to put effort and communication with each other especially between the two genders, and these restrictions weakening and declining their performance in teamwork tasks.So with cross-cultural interactions, I found that Yemeni employees have dramatically changed about their sensitivity with gender space, they have become less protective and conservative while talking to the other gender, also their speech context has become less and have less meditation, so these changes make them believe in fairness and equal opportunities in their workplace. With these changes, I can say that the Yemeni in cross-cultural organisations has an advantage in the teamwork, performance because the team member is open to each other and they will try to give their best performance. Observing the impacts of masculinity and conception of space on Yemeni cross-cultural teamwork performance, I found that cross-cultural Yemeni employees have become less masculine and believed more inequality and performance evaluation rather than gender discrimination, also in the conception of space, cross-cultural interactions changed Yemeni employees sensitivity to space and privacy which enable them to be more flexible, egalitarianism, less restraint, and they tend to participate more in groups and have effective teamwork cooperation. So these impacts of accepting the gender differences and believing in equality and qualifications will improve their efforts and performance. Collectivism and uncertainty avoidance, in these factors, there are not massive changes because the Yemeni culture counts as moderate collectivism and employees tend to prefer working within groups, however, there is only one problem cause less effective cooperation among local employees, which is the communication between the two genders, however, this has been 
narrowed and declined with the cross-cultural interactions.As well, for uncertainty avoidance there is only one big difference between cross-cultural employees and local employees, which is observing the rules, this factor has been improved since the data shows that cross-cultural Yemeni employees are following the rules more than local employees due to the fact that in cross-cultural organization's rules are compulsory and enforced.Finally, the crosscultural impacts on custom differences, there are not substantial transformation along with the important custom factors I have examined in my survey which were; religion, dressing and humane orientation. I found that the two types of Yemeni employees do not have high levels of changes within religion and humane orientation except the fact that they are more open and aware of the fact that everyone is different, and people have different beliefs, traditions and religions. Moreover, for the dressing style, cross-cultural employees have become less traditional and accept the way other cultures dress. Thus, this enables them to accept everyone's differences, and this gives them the ability to understand others and respect their differences which will improve the cross-cultural teams' performance and relationships.

\subsection{Discussion}

This study responds to a recent call for research on the unique aspects of global leadership and the competencies that predict global leadership effectiveness(Avolio, Walumbwa et al. 2009). As hypothesised, results of our rigorous multisource research design show differences in predictors of general leadership effectiveness compared to cross-border leadership effectiveness. Cross-border leaders must work simultaneously with systems, processes, and people from multiple cultures. Thus, cultural intelligence - the capability of functioning effectively in multicultural contexts(Earley and Ang 2003) - is a critical competency of effective globalleaders.Our findings have important theoretical implications. First, as Chiu, Gesturally, and Cheng (2011) point out, the outcomes of globalisation are uncertain. Some academics predict a multicultural global village and others expect clashes between civilisations. As the articles in this issue attest, contextual and psychological factors influence the extent to which intercultural contact activates exclusionary or integrative reactions. For example, Morris, Mor, and Mok (2011) highlight the adaptive value and creative benefits of developing a cosmopolitan identity. Our findings complement this perspective by emphasizing importance of cultural intelligence for leadership effectivenessespecially in high-stakes global encounters, such as cross-border military assignments. Also, our study offers another perspective because we emphasise the value of theory and research on the competencies of global leaders that help them perform in global contexts, rather than focusing on psychological reactions to globalisation. Focusing on competencies suggests exciting opportunities for future research on the dynamic interaction between globalisation and global leaders. The second set of theoretical implications is based on the context-specific relationships demonstrated in this study. Specifically, results suggest that EQ and CQ are complementary because EQ predicted general but not cross-border leadership while CQ predicted cross-border but not general leadership effectiveness. Thiscontrasting pattern reinforces the assertion that domestic leader skillsets do not necessarily generalise to global leader skillsets(Caligiuri and Bennett 2006, Avolio, Walumbwa et al. 2009). Hence, EQ and CQ are related, but distinct forms of social intelligence(Morley, Cerdin et al. 2010), and each has context-specific relevance to different aspects of global leadership effectiveness. Thus, researchers should match types of intelligence to specifics of the situation to maximize thepredictive validity of effectiveness. Our findings also have practical implications for the selection and development of global leaders. First, the significant relationship between general intelligence and both forms of leader effectiveness reinforces the utility of intelligenceas a selection tool for identifying leadership potential. Also, the incremental validity of emotional and cultural intelligence as predictors of leadership effectiveness, over and above previous experience, personality, and general intelligence,confirms predictions that social intelligence also contribute to leadership effectiveness(Riggio and Pirozzolo 2002). Accordingly, managers should consider multiple forms of intelligence when assessing leadership potential, especially when work roles include responsibility for coordinating complex social interactions. Given the differential predictive validity of EQ and CQ about the two types of leadership effectiveness in our study, applying the notion of context similarity and matching types of intelligence with the leadership context should reorganizations enhance their understanding of what predicts global leader effectiveness. This finding should also help organisations understand why leaders who are effective in domesticcontexts may not be effective in crossborder contexts. These insights should help organisations tailor leadership development opportunities to the competency requirements of the situation. When leaders work primarily in domestic settings, organisations should place more emphasis on developing within-culture capabilities, such as EQ. In contrast, when leaders work extensively in international or cross-border settings, organisations should emphasisedevelopment of cross-cultural capabilities, such as $\mathrm{CQ}(\mathrm{Ng}$, Tan et al. 2011).

Despite the strength of our multisource design and support for our predictions, this study has limitations that should help guide future research. First, our cross-sectional design prevents inferences about the causal direction of relationships. Thus, we recommend longitudinal field research that assesses capabilities and leadership effectiveness at multiple points in time. Second, our study was conducted in a military context, and all participants were male. Thus, we recommend caution in generalising our findings to other settings until research can assess 
whether relationships can be replicated in other contexts. To address this need, we recommend future research on different types of intelligence and different aspects of leadership effectiveness in other vocational settings and different cultures(Gelfand, Erez et al. 2007). Third, given that this is the first research, to our knowledge, that proposes and tests an integrated model of three types of intelligence and global leadership effectiveness, the model is necessarily incomplete. We did not consider the indirect effects of mediators or moderators. We recommend future research that "opens the black-box" by focusing on mediating mechanisms that link capabilities with global leader effectiveness. For example, Bass (2002) argued that multiple bits of intelligence are a core element of transformational leadership. Previous research has demonstrated that emotional intelligence in domestic contexts(Rubin, Munz et al. 2005) and cultural intelligence in culturally diverse contexts(Elenkov and Manev 2009) predict transformational leadership behaviour.Judge and Piccolo (2004) provided meta-analytic evidence that transformational leadership behavior's predict leadership effectiveness. Thus, it is plausible that transformational leadership mediates the relationships of emotional and cultural intelligence with leadership effectiveness. Leadermember exchange (LMX) is another plausible mediator. For example, Riggio (2002) suggested that social and emotional intelligence most likely enhance the quality of leader-follower relationships, which then influence effective leadership. In sum, we recommend future research on mediators that link multiple bits of intelligence with leadership effectiveness. We also recommend future research on situational factors that moderate the relationships between multiplebits of intelligence and leadership effectiveness. Judgeet al.'s (2004) meta-analysis, for example, demonstrated that situational stressors influence relationships between general intelligence and leadership effectiveness. Thus, it is possible that situational stressors function as an important boundary condition that qualifies the relationships demonstrated in our study. Given that(Mayer, Roberts et al. 2008) and CQ(Tarique and Takeuchi 2008) are influenced by prior experiences, it is possible that EQ and CQ are especiallyimportant in high-stress situations. Alternatively, it is possible that global identity(Shokef and Erez 2008) functions as a boundary condition that changes the nature of the relationships between leader competencies and leader effectiveness. In sum, we recommend field and experimental research on the extent to which situational stressors moderate the relationships demonstrated in our research. A managerial explanation for culture is; culture is the obtained knowledge that people use to understand experiences and generate social behavior. This means that knowledge forms and creates value, attitudes, performance and influence behavior. According to Greet Hofstede he says "Culture is more often a source of conflict than of synergy. Cultural differences are a trouble, at best, and often a disaster. But if we really want to globalize, there is no way around them, so we better take them for what they are." This means it is not easy for managers to control culture and disasters could happen from having communication along with different cultures, there is also no way to get around dealing with cross-culture differences, especially with the increase of international businesses, as a result It is important for managers to be acquainted with managerial strategies for cross-cultural environment in order to be able to overcome conflicts and positive interactions between cross-cultural teamwork. As I have mentioned earlier cross-culture is very important and can be effective only and only if it was well managed. Philip Iribane (1998) adds that "it is to establish a good mix between the different cultures in a business because every gesture, every word is a proverb that cannot be challenged, and we must put them in a cultural framework. If the cultural diversity is mismanaged, it can be the source of negative impact because many people would feel threatened by working with people of different age, gender or cultural backgrounds. Therefore, this insecurity can have a negative impact on overall productivity. Therefore, it is essential for a manager to identify the cultural specificity of a group to understand the way to react and solve the problems it faces." So, in the following section I will be giving some suggestions and recommendations for managers and employees in cross-cultural organizations, in order to avoid conflicts and disasters from happening, these suggestions are:

$>$ Develop culturally intelligent among employees by training

Work-teams need independence to be creative, but also clear responsibilities

$>$ Work-teams create information overload but have less communication

$>$ Build relationship to have better communication and participation

$>$ Clarify misunderstandings regarding the tasks and clarify their responsibilities

$>$ Ability to utilize creative problem solving

$>$ Managers should create disciplinary among teams for innovative atmosphere

$>$ The Organizational culture should be open to new ideas

$>$ Suppose conflict and arrange to overcome it

\subsection{Conclusion}

In sum, this research begins to add tochilinite understanding of predictors of global leadership effectiveness and how the nomological networks of leadership effectiveness differ in different contexts. Most important, results demonstrate the critical importance of CQ in predicting leadership effectiveness in cross-bordercontexts. We recommend future research on IQ, EQ, and CQ as well as other intelligence in predicting different types of leadership effectiveness in both domestic and cross-cultural contexts. Globalization is an important element for 
each country's success and improvements, and this made it imperative for people to travel between countries, it is very hard for any country to close their doors and remain isolated from the outside world, because nowadays country is a complementary to the other country, they complete each other and make things easier and sufficient especially if we talk about the economic condition. Consequently, it is very important for people to adapt and accept other's cultures and differences. Hence, Cross-cultural employees can be the key success for organizations if managers were able to have effective strategies, so international managers must be capable of cross-cultural management; and if these differences are recognized and solve, the teamwork performance will improve and teams can save time, reduce costs and increase profitability, and achieve goals. From this study and survey, I have accomplished I came to realize that cultural diversity is more effective in Yemeni employees' performance and teamwork, productivity; these positive impacts include flexibility, acceptance of differences, better decision making, greater creativity, higher opportunities for innovation, greater success in international activities and businesses. However, where local Yemeni employees are less productive, reluctant, have gender space which impacts the effectiveness of teamwork, communication, unfairness, and has high privacy levels which make it hard to communicate and participate with others. There is a study made in 1993 by Watson, Kannales, and Michaelsen, they say: "compared to homogeneous groups, culturally diverse groups are more effective both in social interactions at the level of job performance" Furthermore, there have been many cross-cultural organizations such as; bank of Montreal in Canada says that the cross-cultural differences and diversity among their employees have actually a positive contribution to strengthening and increasing their business' competitive advantages. To summarize this paper, I can say that there is a huge change among Yemeni employee's behavior and performance, which is influenced by cross-cultural organizations and employees' differences. Personally, I think that these changes count as advantages for the teamwork, performance and creativity, it changed local Yemeni employees to be more flexible, tolerant, responsible, open minded, more aware of the female roles in society and their importance of participating in organizations. The cross-cultural Yemeni employees are less conservative, communicate more with females and admire their roles, their creativity and performance are increasing since they feel the fairness in evaluation and power distribution, the become more motivated with the equality. Therefore, all these changes have affirmative direct and indirect impacts on the relationship among employees, which will extremely impact their performance as teamwork and the outcome of their interaction.

\section{References}

Ang, S. and L. Van Dyne (2008). "Conceptualization of cultural intelligence: Definition, distinctiveness, and nomological network." Handbook of cultural intelligence: Theory, measurement, and applications: 3-15.

Ang, S. and L. Van Dyne (2015). Handbook of cultural intelligence, Routledge.

Ang, S., L. Van Dyne, C. Koh, K. Y. Ng, K. J. Templer, C. Tay and N. A. Chandrasekar (2007). "Cultural intelligence: Its measurement and effects on cultural judgment and decision making, cultural adaptation and task performance." Management and organization review3(3): 335-371.

Avolio, B. J., F. O. Walumbwa and T. J. Weber (2009). "Leadership: Current theories, research, and future directions." Annual review of psychology60: 421-449.

Bandura, A. (2002). "Social cognitive theory in cultural context." Applied Psychology51(2): 269-290.

Blum-Kulka, S., J. House and G. Kasper (1989). Cross-cultural pragmatics: Requests and apologies, Ablex Pub.

Caligiuri, P. M. and W. Bennett (2006). "Performance measurement in a cross-national context." Performance measurement: Current perspectives and future challenges: 227-244.

Campbell, J. P., R. A. McCloy, S. H. Oppler and C. E. Sager (1993). "A theory of performance." Personnel selection in organizations 3570 .

Chen, G., B. L. Kirkman, K. Kim, C. I. Farh and S. Tangirala (2010). "When does cross-cultural motivation enhance expatriate effectiveness? A multilevel investigation of the moderating roles of subsidiary support and cultural distance." Academy of Management Journal53(5): 1110-1130.

Dau, L. A. (2016). "Biculturalism, team performance, and cultural-faultline bridges." Journal of International Management22(1): 48-62.

Deci, E. L. and R. Ryan (1985). Intrinsic motivation and self-determination in human behavior. New York and London, Plenum.

Dickson, M. W., D. N. Den Hartog and J. K. Mitchelson (2003). "Research on leadership in a cross-cultural context: Making progress, and raising new questions." The leadership quarterly14(6): 729-768.

Earley, P. C. and S. Ang (2003). Cultural intelligence: Individual interactions across cultures, Stanford University Press.

Eccles, J. S. and A. Wigfield (2002). "Motivational beliefs, values, and goals." Annual review of psychology53(1): 109-132.

Elenkov, D. S. and I. M. Manev (2009). "Senior expatriate leadership's effects on innovation and the role of cultural intelligence." Journal of World Business44(4): 357-369.

Gelfand, M. J., M. Erez and Z. Aycan (2007). "Cross-cultural organizational behavior." Annu. Rev. Psychol.58: 
479-514.

Gregersen, H. B., A. J. Morrison and J. S. Black (1998). "Developing leaders for the global frontier." MIT Sloan Management Review40(1): 21.

Groves, K. S. and A. E. Feyerherm (2011). "Leader cultural intelligence in context: Testing the moderating effects of team cultural diversity on leader and team performance." Group \& Organization Management: 1059601111415664

House, R. J., P. J. Hanges, M. Javidan, P. W. Dorfman and V. Gupta (2004). Culture, leadership, and organizations: The GLOBE study of 62 societies, Sage publications.

Imai, L. and M. J. Gelfand (2010). "The culturally intelligent negotiator: The impact of cultural intelligence (CQ) on negotiation sequences and outcomes." Organizational Behavior and Human Decision Processes112(2): 83-98.

Johns, G. (2006). "The essential impact of context on organizational behavior." Academy of management review31(2): 386-408.

Judge, T. A., A. E. Colbert and R. Ilies (2004). "Intelligence and leadership: a quantitative review and test of theoretical propositions." Journal of Applied Psychology89(3): 542.

Kim, Y. J. and L. Van Dyne (2012). "Cultural intelligence and international leadership potential: The importance of contact for members of the majority." Applied psychology61(2): 272-294.

Mayer, J. D., R. D. Roberts and S. G. Barsade (2008). "Human abilities: Emotional intelligence." Annu. Rev. Psychol.59: 507-536.

Mladenović, S. S., I. Mladenović, M. Milovančević and N. Denić (2017). "Cross-cultural dimensions influence on business internationalization by soft computing technique." Computers in Human Behavior75: 865-869.

Morley, M. J., J.-L. Cerdin and T. Moon (2010). "Emotional intelligence correlates of the four-factor model of cultural intelligence." Journal of Managerial Psychology25(8): 876-898.

Mumford, M. D., S. J. Zaccaro, F. D. Harding, T. O. Jacobs and E. A. Fleishman (2000). "Leadership skills for a changing world: Solving complex social problems." The Leadership Quarterly11(1): 11-35.

Ng, K.-Y., M. L. Tan, S. Ang, I. A. Burton and J. Spender (2011). "Culture capital and cosmopolitan human capital: The impact of global mindset and organizational routines on developing cultural intelligence and international experiences in organizations." The Oxford handbook of human capital: 96-119.

Nielsen, B. B. and S. Nielsen (2011). "The role of top management team international orientation in international strategic decision-making: The choice of foreign entry mode." Journal of World Business46(2): 185-193.

Riggio, R. E. and F. J. Pirozzolo (2002). "Multiple intelligences and leadership: Implications for leadership research and training." Multiple intelligences and leadership: 241-250.

Rockstuhl, T. and K.-Y. Ng (2008). "The effects of cultural intelligence on interpersonal trust in multicultural teams." Handbook of cultural intelligence: Theory, measurement, and applications: 206-220.

Rockstuhl, T., S. Seiler, S. Ang, L. Van Dyne and H. Annen (2011). "Beyond general intelligence (IQ) and emotional intelligence (EQ): The role of cultural intelligence (CQ) on cross-border leadership effectiveness in a globalized world." Journal of Social Issues67(4): 825-840.

Rubin, R. S., D. C. Munz and W. H. Bommer (2005). "Leading from within: The effects of emotion recognition and personality on transformational leadership behavior." Academy of Management Journal48(5): 845-858.

Shin, S. J., F. P. Morgeson and M. A. Campion (2007). "What you do depends on where you are: Understanding how domestic and expatriate work requirements depend upon the cultural context." Journal of International Business Studies38(1): 64-83.

Shokef, E. and M. Erez (2008). "Cultural intelligence and global identity in multicultural teams." Handbook of cultural intelligence: Theory, measurement, and applications: 177-191.

Tajfel, H. (1981). Human groups and social categories: Studies in social psychology, CUP Archive.

Tarique, I. and R. Takeuchi (2008). "Developing cultural intelligence: The roles of international nonwork experiences." Handbook of cultural intelligence: Theory, measurement, and applications: 56-70.

Torelli, C. J., C. Y. Chiu, K. p. Tam, A. K. Au and H. T. Keh (2011). "Exclusionary reactions to foreign cultures: Effects of simultaneous exposure to cultures in globalized space." Journal of Social Issues67(4): 716-742.

Triandis, H. C. (2006). "Cultural intelligence in organizations." Group \& Organization Management31(1): 20-26.

Turner, J. C., M. A. Hogg, P. J. Oakes, S. D. Reicher and M. S. Wetherell (1987). Rediscovering the social group: A self-categorization theory, Basil Blackwell.

Ward, A.-K. and E. C. Ravlin (2017). "Building influence as an outsider: A theoretical approach to cross-cultural impression management." Human Resource Management Review27(3): 491-506. 